\title{
Factors Associated with Hypertensive Disorders of Pregnancy in Public Maternities of the City of Parakou In 2019
}

\author{
M. V. Vodouhe ${ }^{1 *}$, A. A. A. Obossou ${ }^{1}$, R. Atade ${ }^{1}$, S. Kpadonou1, \\ K. Salifou' ${ }^{1}$, K. N'tcha ${ }^{2}$, N. F. M. Hounkponou' ${ }^{1}$, I. R. Sidi ${ }^{1}$ \\ ${ }^{1}$ Obstetric Gynecology Service of Departmental University Hospital Center of Borgou and Alibori, Parakou, Bénin \\ ${ }^{2}$ Laboratory of Epidemiology of Chronic and Neurological Diseases (LEMACEN), Faculty of Health Sciences, University of \\ Abomey-Calavi, Abomey-Calavi, Benin \\ Email: *hublo.vinadou @gmail.com
}

How to cite this paper: Vodouhe, M.V., Obossou, A.A.A., Atade, R., Kpadonou, S., Salifou, K., N’tcha, K., Hounkponou, N.F.M. and Sidi, I.R. (2021) Factors Associated with Hypertensive Disorders of Pregnancy in Public Maternities of the City of Parakou In 2019. Open Journal of Obstetrics and Gynecology, $11,868-878$

https://doi.org/10.4236/ojog.2021.117081

Received: June 2, 2021

Accepted: July 16, 2021

Published: July 19, 2021

Copyright $\odot 2021$ by author(s) and Scientific Research Publishing Inc. This work is licensed under the Creative Commons Attribution International License (CC BY 4.0).

http://creativecommons.org/licenses/by/4.0/

\begin{abstract}
The purpose of this study was to evaluate the prevalence of Hypertensive Disorders in Pregnancy (HDP) and to determine the factors associated with them in the city of Parakou in Benin, a West African country. Method: It has been a descriptive cross-sectional study with a prospective collection of data using a questionnaire in prenatal consultation in the health center of Parakou's commune for 4 months (May 1 to August 31, 2019). Result: A proportion of $8.2 \%$ (55/671) of the pregnancy had the hypertensive disorders of pregnancy. The Gestational HyperTension was the most common type of arterial hypertension (AHT) with a proportion of $49.1 \%$. The factors associated with HDP were the age of 30 to 34 (OR: 11.9; 95\% CI: $1.54-92.29 ; p=$ $0.0346)$, the family history of Arterial HyperTension (AHT) (OR: 1.5; 95\% CI: $1.03-4.66 ; p=0.0481$ ), the BMI > 30 (OR:14.2; 95\% IC: $7.02-28.69 ; p=$ $0.0235)$, being married or in a common-law relationship ( $\mathrm{OR}=2.51 ; 95 \% \mathrm{CI}$ : 1.30 - 4.86; $p=0.0412$ ), the stress (OR: $2.0 ; 95 \%$ CI:1.09 - 3.32; $p=0.0209$ ), the history of HDP (OR: 9.0; 95\% CI: $2.53-15.23$; $p<0.05$ ). Conclusion: HDP are common in Parakou. Some factors previously described in the literature are associated with them.
\end{abstract}

\section{Keywords}

Hypertensive Disorders, Pregnancy, Bénin, West Africa

\section{Introduction}

Maternal mortality is still very high in the world, particularly in under-developed 
countries. One of the causes is represented by Hypertensive Disorders in Pregnancy (HDP). HDP are major causes of severe morbidity, long-term disability and maternal and neonatal mortality [1]. According to the literature, they complicate $10 \%-15 \%$ of pregnancies (Koopmans CM, 2009). In West Africa, old studies reported a high hospital frequency of HDP [2] [3]. The socio-demographic characteristics of populations change over time and can change the frequency of certain pathologies. The frequency of HDP is increasing in the world in recent years probably due to the increase in the age and Body Mass Index of parturients [4] [5]. Few recent studies have looked at the HDP population in West Africa. The purpose of this study was to assess the prevalence of HDP and to determine the factors associated with them in the city of Parakou in Benin, a country of West Africa.

\section{Method}

This was a descriptive cross-sectional study for analytical purposes with prospective data collection. Data collection was done through direct interviews using a questionnaire. This collection took place in the period from May 1 to August 31, 2019 (4 months).

Our study focused on the pregnant women, whose pregnancy was confirmed by ultrasound or biological test of pregnancy, who came for consultation in one of the maternity hospitals in the city of Parakou.

sampling:

Sample size:

The sample size was determined by Schwartz's formula

$$
n=t^{2} \times p \times(1-p) / m^{2}
$$

$n$ : Minimum sample size for significant results for an event and a 5\% risk level; $t$. Confidence level (the typical $95 \%$ confidence level will be 1.96); $p$ : estimated proportion of the population with the characteristic (10\%); m: Margin of error (set at $3 \%$;

$$
\begin{aligned}
n & =\frac{1.96 * 1.96 * 0.1 *(1-0.1)}{0.0236 * 0.0236} . \\
& =620
\end{aligned}
$$

We have majo of this size of $10 \%$ : The sample size was finally 682 .

\section{Sampling technique:}

We took into account the relative proportions of pregnant women who had consulted in each of the maternity hospitals in the city of Parakou during the month preceding the start of the survey, to determine their contribution to the size $\mathrm{n}$ of the sample. These proportions were determined by the ratio of the number of pregnant women who had consulted the previous month in each maternity unit to the total number of pregnant women who had consulted in all public maternity hospitals in the city of Parakou in 2019. This is summarized in Table 1. 
Table 1. Distribution of the sample size according to maternity hospitals in the city of Parakou in 2019.

\begin{tabular}{cccc}
\hline Public maternity & $\begin{array}{c}\text { Number of pregnant } \\
\text { women the previous month }\end{array}$ & $\begin{array}{c}\text { Proportion } \\
(\%)\end{array}$ & $\begin{array}{c}\text { Number of pregnant } \\
\text { women to be selected }\end{array}$ \\
\hline BA/DUHC & 58 & 2 & 13 \\
Army Training Hospital & 152 & 5 & 33 \\
CMS de la Garnison/Parakou & 117 & 4 & 25 \\
HC Communal of Parakou & 593 & 19 & 128 \\
HC of Madina & 398 & 13 & 86 \\
HC of Kpebie & 472 & 15 & 102 \\
HC of Tourou & 231 & 7 & 50 \\
HC of Banikanni & 472 & 15 & 102 \\
HC of Zongo & 324 & 10 & 70 \\
HC of Ganou & 339 & 11 & 73 \\
Total & 3156 & 100 & 682 \\
\hline
\end{tabular}

BA/DUHC: Borgou and Alibori Departmental University Hospital Center; MSC: Medical-Social Center; HC: Health Center.

\section{Selection of pregnant women:}

In each maternity unit, we performed a simple random survey technique. Indeed, in each maternity unit, the list of women in antenatal care is known, so to select the list of women $(\mathrm{N})$ to be included in the study, we proceeded as follows:

1) number women from 1 to $n$,

2) Generate a random number for each unit in the survey base (from a epi 6 software),

3) Order women according to random number,

4) Take the $n$ first women.

\section{Tools and data collection techniques:}

It was a structured questionnaire. The questionnaire was based on a previous study on hypertension in pregnancy at the University Hospital of Tokoin in Togo [3]. In each of the health centers participating in the study, a midwife was recruited for data collection. Data collection in all study centres was coordinated by a $7^{\text {th }}$ year medical student at the Faculty of Medicine in Parakou. The data had been collected during an investigating-respondent interview; the dependent variable was Arterial HyperTension (AHT) during pregnancy. Independent variables were the type of AHT during pregnancy, socio-demographic variables (age, body mass index (BMI), occupation, level of education, stress, socio-économic level), Family history (AHT, diabetes), obstetric history (Gestite, preeclampsia, eclampsia, gestational hypertension), the characteristics of current pregnancy (gestational age, prenatal follow-up). The pregnant women's height and weight were measured using a measuring rod and a bathroom scale, respectively. Proteinuria had been tested with a urine dipstick (URS-10AR). Arterial Pressure (AP) was measured in women in a sitting position in a medical setting, after at least $5 \mathrm{mi}$ - 
nutes of rest, using an approved electronic humeral device: Omron M6 Comfort R. The diagnosis of Arterial HyperTension (AHT) was made according to the standards of the French Society of Arterial Hypertension (SFHTA): AP $\geq 140 / 90 \mathrm{mmHg}$ [6]. Gestational Hypertension was defined as hypertension discovered after the $20^{\text {th }}$ week of amenorrhea, without proteinuria, in a non-hypertensive woman before pregnancy, with AP returned to normal within 6 weeks after childbirth. We spoke of preeclampsia when this hypertension was associated with proteinuria $>$ $300 \mathrm{mg} / 24 \mathrm{~h}$ (++ on the urine dipstick). Chronic hypertension was defined as hypertension existing before pregnancy without proteinuria. Obesity was defined as a body mass index $(\mathrm{BMI}) \geq 30 \mathrm{~kg} / \mathrm{m}^{2}$ in the first trimester of pregnancy. We considered as having a low socio-economic level the patients who had a monthly income lower than the General Interprofessional Minimum Wage (40.000 FCFA, \$ 73.77, in Benin) [7]. Stress was defined by a Cungi score > 30 [8].

\section{Processing and analyzing data:}

A double data entry was made in the EPI Data 3.1 software. Analyzing data was done using the EPI Info version 7 software. The central tenderness and dispersion parameters used for the description of quantiting variables. And the proportions with their confidence interval (CI) for the qualitative variables. the means have been presented with their standard deviation. The uncorrected $\mathrm{X}^{2}$ statistical test was used to compare the modalities of each independent variable when the theoretical sizes greater than or equal to 5 and the corrected X2 test when at least one of the theoretical sizes is less than or equal to 5 . The difference was statistically significant for a p-value less than 0.05. The software Microsoft Word 2010 was used for entry of the publication and Excel 2010 for the organization of the data in the form of tables.

\section{Ethical considerations:}

The protocol for carrying out this study was submitted and validated by the Local Ethics Committee for Biomedical Research of the University of Parakou (CLERB-UP) under number REF 0010/CLERB-UP/P/SP/R /HER. The responsible of the maternity hospitals which took part in the study gave their approval for its realization. The written consents of the subjects surveyed were obtained before their participation in the study. The anonymity and confidentiality of the data had been respected.

\section{Result}

We recorded 682 pregnant women in the public maternity hospitals of Parakou. Eleven of which were excluded for insufficient information on the survey form. 8.2\% (55/671) of pregnant women had Hypertensive Disorders in Pregnancy (HDP).

Gestational hypertension was the most common type of HDP with a proportion of $49.1 \%$ (Table 2).

Socio-demographic characteristics:

The average age of the pregnant women who had Hypertensive Disorders in 
Pregnancy (HDP) was 27.5 years \pm 4.8 years with extremes of 18 years and 36 years. The proportion of [20 - 24] years was the highest (30.9\%) (Table 3 ). The majority of respondents were married (78.2\%). The most represented level of instruction was secondary with a proportion of $49.1 \%$. Most of the pregnant women were housewives $(36.4 \%)$. A proportion of $49.1 \%$ of them had reported frequently living stress situations. This information is described in Table 3.

Table 2. Distribution by type of disorders hypertensive in pregnancy.

\begin{tabular}{ccc}
\hline & Effective & Proportion (\%) \\
\hline Chronic hypertension & 11 & 20.0 \\
Gestational hypertension & 27 & 49.1 \\
Preeclampsia & 17 & 30.9 \\
Total & 55 & 100.0 \\
\hline
\end{tabular}

Table 3. Distribution according to socio-demographic characteristics (Parakou, 2019).

\begin{tabular}{|c|c|c|}
\hline & Effective & Proportion (\%) \\
\hline \multicolumn{3}{|l|}{ Age (years) } \\
\hline$\leq 19$ & 1 & 1.8 \\
\hline$[20-24]$ & 17 & 30.9 \\
\hline [25 - 29] & 16 & 29.1 \\
\hline$[30-34]$ & 16 & 29.1 \\
\hline [35 - 39] & 5 & 9.1 \\
\hline Total & 55 & 100 \\
\hline \multicolumn{3}{|l|}{ BMI } \\
\hline [19 - 25] & 18 & 32.7 \\
\hline [25 - 30] & 14 & 25.4 \\
\hline$>30$ & 23 & 41.8 \\
\hline Total & 55 & 100 \\
\hline \multicolumn{3}{|c|}{ Educational level } \\
\hline No schooling & 19 & 34.5 \\
\hline primary & 7 & 12.7 \\
\hline secondary & 27 & 49.1 \\
\hline university & 2 & 3.6 \\
\hline Total & 55 & 100 \\
\hline \multicolumn{3}{|l|}{ Profession } \\
\hline reseller & 3 & 5.4 \\
\hline craftswoman & 2 & 3.6 \\
\hline Housewife & 20 & 36.4 \\
\hline Civil servant & 15 & 27.3 \\
\hline
\end{tabular}




\section{Continued}

\begin{tabular}{ccc}
\hline student & 2 & 3.6 \\
schoolboy & 3 & 5.4 \\
mercant & 10 & 18.2 \\
Total & 55 & 100 \\
Stress & & \\
No & 28 & 50.9 \\
yes & 27 & 49.1 \\
Total & 55 & 100 \\
Socioeconomic level & & \\
Medium & 55 & 100 \\
Total & 55 & 100 \\
\hline
\end{tabular}

Table 4. Distribution by family history.

\begin{tabular}{ccc}
\hline & Effective & Proportion (\%) \\
\hline $\begin{array}{c}\text { Family history } \\
\text { Diabetes }\end{array}$ & & \\
no & 50 & 90.9 \\
yes & 5 & 9.1 \\
Hypertension & & \\
no & 44 & 80 \\
yes & 11 & 20 \\
Total & 55 & 100
\end{tabular}

History of pregnant women with Hypertensive Disorders in Pregnancy:

The pregnant women surveyed had a family history of diabetes and arterial hypertension in $9.1 \%$ and $20 \%$ of cases, respectively (Table 4 ).

Most pregnant women who had HDP were multigest (78.2\%). 32.7\% (18/55) of them had a history of HDP (gestational hypertension $10.9 \%$, preeclampsia $7.3 \%$, eclampsia $1.8 \%$, chronic hypertension 7\%) (Table 5).

The characteristics of the current pregnancy:

Most pregnant women had a gestational age greater than or equal to 32 weeks (45.5\%). A proportion of $5.5 \%$ of the pregnant women had gestational diabetes (Table 6).

Factors associated with Hypertensive disorders of pregnancy:

The Factors associated with HDP were 30 to 34 years of age (OR = 11.95; 95\% CI: 1.54 - 92.29; $p=0.0346)$, family history of Arterial Hyper Tension (AHT) (OR = 1.52; 95\% CI: 1.03 - 4.66; $p=0.0145), \mathrm{BMI}>30$ (OR=14.19; 95\% CI: $7.02-28.69 ; p$ $=0.0235)$, being married or in a common-law relationship $(\mathrm{OR}=2.51 ; 95 \% \mathrm{CI}: 1.30$ - 4.86; $p=0.0412$ ), stress (OR $=2.03$; 95\% CI: 1.09 - 3,32; $p=0.0209$ ), history of Hypertensive Disorders in Pregnancy (OR = 9.00; 95\% CI: $2.53-15.23 ; p<0.05$ ). 
Table 5. Distribution according to obstetric history (Parakou, 2019).

\begin{tabular}{|c|c|c|}
\hline & Effectif & Proportion (\%) \\
\hline \multicolumn{3}{|l|}{ Gestite } \\
\hline Primigest & 12 & 21.8 \\
\hline Multigest & 43 & 78.2 \\
\hline Total & 55 & 100 \\
\hline \multicolumn{3}{|l|}{ Gestational hypertension } \\
\hline no & 49 & 89.1 \\
\hline yes & 6 & 10.9 \\
\hline Total & 55 & 100 \\
\hline \multicolumn{3}{|l|}{ Eclampsia } \\
\hline no & 54 & 98.2 \\
\hline yes & 1 & 1.8 \\
\hline Total & 55 & 100 \\
\hline \multicolumn{3}{|l|}{ Prééclampsia } \\
\hline no & 51 & 92,7 \\
\hline yes & 4 & 7,3 \\
\hline Total & 55 & 100 \\
\hline Chronic hypertension & 51 & 93 \\
\hline no yes & 4 & 7 \\
\hline Total & 55 & 100 \\
\hline
\end{tabular}

Primigest (1), Multigest (>1).

Table 6. Distribution according to the characteristics of the current pregnancy (Parakou, 2019).

\begin{tabular}{ccc}
\hline & Effective & Proportion (\%) \\
\hline Gestational age & 5 & 9.1 \\
$<22$ WA & 12 & 21.8 \\
22 SA - 28 WA & 13 & 32.6 \\
28 WA - 32 WA & 25 & 45.5 \\
$\geq 32$ WA & 55 & 100 \\
Total & & \\
Pregnancy follow up & 55 & 100 \\
yes & 55 & 100 \\
Total & & 10.9 \\
Number of ANC & 6 & 16.4 \\
2 ANC & 9 & 72.7 \\
3 ANC & 40 & 100 \\
At least 4 ANC & 55 &
\end{tabular}

ANC: AnteNatal Consultation. 
There was no significant association between HDP and gestite $(p=0.2315)$.

These results can be found in Table 7 .

Table 7. Factors associated with Hypertensive Disorders of Pregnancy (HDP) (Parakou, 2019).

\begin{tabular}{|c|c|c|c|c|c|c|}
\hline & \multirow{2}{*}{ Total } & \multicolumn{2}{|c|}{ HDP } & \multirow{2}{*}{ OR } & \multirow{2}{*}{$95 \% \mathrm{CI}$} & \multirow{2}{*}{ p-value } \\
\hline & & Yes (n) & $\%$ & & & \\
\hline Age & & & & & & 0.0346 \\
\hline$\geq 19$ & 72 & 1 & 14 & Reference & - & \\
\hline$[20-24]$ & 210 & 17 & 8.1 & 6.3 & $0.82-47.86$ & \\
\hline [25 - 29] & 216 & 16 & 7.4 & 5.7 & $0.74-43.61$ & \\
\hline$[30-34]$ & 111 & 16 & 14.4 & 11.9 & $1.54-92.29$ & \\
\hline [34 - 39] & 42 & 5 & 11.9 & 9.6 & $1.08-85.18$ & \\
\hline$[40-44]$ & 9 & 0 & 0.0 & - & - & \\
\hline$\geq 44$ & 11 & 0 & 0,0 & - & - & \\
\hline Total & 671 & 55 & 8,2 & & & \\
\hline Marital status & & & & & & 0.0412 \\
\hline Married/common-law relationship & 405 & 43 & 10.6 & 2.5 & $1.30-4.86$ & \\
\hline Single & 266 & 12 & 4.5 & Reference & - & \\
\hline Total & 671 & 55 & 8.2 & & & \\
\hline Family history & & & & & & 0.0145 \\
\hline Diabetes & 52 & 5 & 9.6 & Reference & - & \\
\hline Hypertension & 79 & 11 & 13.9 & 1.5 & $1.03-4.66$ & 0.0145 \\
\hline Total & 131 & 16 & 12.2 & & & \\
\hline BMI & & & & & & 0.0235 \\
\hline$<19$ & 34 & 0 & 0.0 & - & - & \\
\hline $19-25$ & 471 & 18 & 3.8 & Reference & - & \\
\hline $25-30$ & 105 & 15 & 14.3 & 4.2 & $2.03-8.63$ & \\
\hline$>30$ & 61 & 22 & 36.1 & 14.2 & $7.02-28.69$ & \\
\hline Total & 671 & 55 & 8.2 & & & \\
\hline Stress & 234 & 27 & 11.5 & 2.0 & $1.09-3.32$ & 0.0209 \\
\hline Gestite & & & & & & 0.2315 \\
\hline Primigest & 188 & 12 & 6.4 & Reference & - & \\
\hline Multigest & 483 & 43 & 8.9 & 1.4 & $0.73-2.78$ & \\
\hline Total & 671 & 55 & 8.2 & & & \\
\hline Obstetric history & & & & & & 0.0156 \\
\hline Chronic hypertension & 8 & 7 & 87.5 & 9.0 & $2.53-15.23$ & \\
\hline Gestational H-hypertension & 12 & 6 & 50.0 & 7.0 & $0.64-75.74$ & \\
\hline Preeclampsia & 12 & 4 & 33.3 & 3.5 & $0.31-39.15$ & \\
\hline Fœtal Death In Utero & 8 & 1 & 12.5 & Reference & - & \\
\hline Total & 40 & 18 & 45.0 & & & \\
\hline Pregnancy pathologie & & & & & & 0.4179 \\
\hline Gestational Diabete & 25 & 3 & 12.0 & 2.12 & $0.48-5.75$ & \\
\hline
\end{tabular}




\section{Discussion}

Our study took place over a period of four months from May 1 to August 31, 2019. This study focused on pregnant women received in prenatal consultation in public maternity hospitals in the city of Parakou. It allowed us to determine the prevalence and factors associated with Hypertensive Disorders in Pregnancy (HDP) in the city of Parakou.

We observed a prevalence of $8.2 \%$ of Hypertensive Disorders in Pregnancy. This frequency is close to that reported by Oladélé FC and al. [9] in Nigeria (7.2\%). This frequency is lower than that reported by Baragou S. and al. [3] in Togo (12.3\%) who had carried out their study in a reference health center where there was a higher concentration of cases, whereas our study and that of Oladélé and al. [9] had been carried out both in peripheral health centers and in reference health centers. In the literature, most authors report that hypertension complicates $10 \%$ to $15 \%$ of pregnancies [10]. The frequency of the association of arterial hypertension and pregnancy depends on the criteria for inclusion in the different series and on the high frequency of risk factors in the population studied [11]. Some authors think that this prevalence is often underestimated by the classic taking of the Artery Pressure in the office. These authors propose Ambulatory Blood Pressure Measurement (ABPM) more sensitive and more specific, as a reference method for detecting HDP [6] [12].

In our series, the gestational hypertension is the clinical form of HDP most represented (49\%). This result is different from those of Baragou and al. [3] in Lomé and Hounkponou and al. [13] in Parakou who had reported that the preeclampsia was the most represented in their study. This difference could be explained by the fact that these authors had completed their study in reference centers which received the risk forms of HDP: preeclampsia and its complications.

We found that a high proportion (41.8\%) of the pregnant women who had HDP were obese. Obesity is a pandemic according to World Health Organisation data in 2003 [14]. Africa is also concerned with frequency thresholds greater than $30 \%$ in adults in some countries [15]. Our results showed that obesity was a factor associated with HDP. In the literature it had already been established that obesity was a risk factor for Gestational Hypertension and Preeclampsia [16] [17].

Many studies had reported that age over 35 or 40 years increases the risk of gestational hypertension and preeclampsia [16] [18]. We found that the $30-34$ years age group was associated with HDP. Authors such as Hounkponou NFM and al. [13], Bah A.O. and al. [2] had rather found the young maternal age as a risk factor. These results could be partially explained by the fact that primiparity is a risk factor for preeclampsia [16] and these studies were carried out in regions where women usually contract their first pregnancy at a young age.

A personal history of gestational hypertension or preeclampsia was factors associated with HDP $(p<0.05)$. This result is similar to that of Baragou S. and al. [3]. Duckitt K and al. [16] had also found a similar result after a review of the 
literature on risk factors for preclampsia during pregnancy.

A family history of hypertension was statistically associated with HDP ( $p<$ 0.05). A similar result was reported by Bah O.A. and al. [2] and Baragou S and al. [3]. This presence of hypertension in the family history confirmed the idea that this is a risk factor for arterial hypertension during pregnancy, with probably the hypothesis of genetic support in the genesis of the pathology.

We did not determine the proportion of chronic hypertension complicated by preeclampsia. This is a limitation of our study.

\section{Conclusion}

Hypertensive Disorders in Pregnancy are frequent in the city of Parakou. Certain associated factors previously described in the literature are associated with them. Prevention measures that take into account these associated factors will certainly reduce the incidence of this condition and its complications.

\section{Conflicts of Interest}

The authors declare no conflicts of interest regarding the publication of this paper.

\section{References}

[1] Organisation Mondiale de la Santé (2014) Recommandation de l'OMS pour la prévention et le traitement de la prééclampsie et de l'éclampsie. Organisation Mondiale de la Santé, Genève.

[2] Bah, A.O., Diallo, M.H., Diallo, A.A.S., Keita, N. and Diallo, M.S. (2000) Hypertension artérielle et grossesse: Aspects épidémiologiques et facteurs de risque. Médecine $d^{d}$ Afrique Noire, 47, 422-425.

[3] Baragou, S., Goeh-Akue, E., Pio, M., Afassinou, Y.M. and Atta, B. (2014) Hypertension artérielle et grossesse à Lomé (Afrique sub-saharienne): Aspects épidémiologiques, diagnostiques et facteurs de risque. Annales de Cardiologie et d Angéiologie, 63, 145-150. https://doi.org/10.1016/j.ancard.2014.05.006

[4] Wallis, A.B., Saftlas, A.F., Hsia, J. and Atrash, H.K. (2008) Secular Trends in the Rates of Preeclampsia, Eclampsia, and Gestational Hypertension, United States, 1987-2004. American Journal of Hypertension, 21, 521-526. https://doi.org/10.1038/ajh.2008.20

[5] Sibai, B.M. (2015) First-Trimester Screening with Combined Maternal Clinical Factors, Biophysical and Biomarkers to Predict Preterm Pre-Eclampsia and Hypertensive Disorders: Are They Ready for Clinical Use? BJOG: An International Journal of Obstetrics \& Gynaecology, 122, 282-283. https://doi.org/10.1111/1471-0528.13052

[6] Mounier-Vehier, C. (2016) Hypertension and Pregnancy: A New Expert Consensus Statement. Bulletin de P Academie Nationale de Médecine, 200, 1453-1463. https://doi.org/10.1016/S0001-4079(19)30616-8

[7] République du Bénin (2000) Relèvement du salaire minimum interprofessionnel garanti (SMIG). DECRET No. 2000-162, Ministère L'économie et des Finances, Paris.

[8] Cungi, C., Bouhana, S., Degoul, G. and Bibollet, D. (1995) Deux échelles brèves 
d'auto-évaluation des stresseurs et du stress. Oxford University Press, Oxford. https://studylibfr.com/doc/2483704

[9] Oladele, F.C., Charles-Davies, M.A., Ojengbede, O.A. and Agbedana, E.O. (2018) Prevalence of Hypertensive Disorders in Pregnant Nigerians and Their Related Factors. African Journal of Medical and Health Sciences, 47, 297-305.

[10] Koopmans, C.M., Bijlenga, D., Groen, H., Vijgen, S.M.C., Aarnoudse, J.G., Bekedam, D.J., et al. (2009) Induction of Labour versus Expectant Monitoring for Gestational Hypertension or Mild Pre-Eclampsia after 36 Weeks' Gestation (HYPITAT): A Multicentre, Open-Label Randomised Controlled Trial. Lancet, 374, 979-988. https://doi.org/10.1016/S0140-6736(09)60736-4

[11] World Health Organization (1988) Geographic Variation in the Incidence of Hypertension in Pregnancy. World Health Organization International Collaborative Study of Hypertensive Disorders of Pregnancy. American Journal of Obstetrics \& Gynecology, 158, 80-83. https://doi.org/10.5555/uri:pii:000293788890782X

[12] Ayala, D.E. and Hermida, R.C. (2013) Ambulatory Blood Pressure Monitoring for the Early Identification of Hypertension in Pregnancy. Chronobiology International, 30, 233-259. https://doi.org/10.3109/07420528.2012.714687

[13] Hounkponou, N.F.M., Codjo, L.H., Sidi, R., Dohou, S.H., Djoh Ndian, K.I. and Houenassi, M.D. (2017) Prévalence et facteurs de risque des syndromes vasculo-rénaux en milieu hospitalier à Parakou (Bénin) en 2015. Médecine d Afrique Noire, 6440, 236-242.

[14] Organisation Mondiale de la Santé. (2003) Obésité: Prévention et prise en charge de l'épidémie mondiale. Organisation Mondiale de la Santé, Genève.

[15] Correia, J., Pataky, Z. and Golay, A. (2014) Comprendre l'obésité en Afrique: Poids du développement et des représentations. Revue Médicale Suisse, 10, 712-716.

[16] Duckitt, K. and Harrington, D. (2005) Risk Factors for Pre-Eclampsia at Antenatal Booking: Systematic Review of Controlled Studies. BMJ, 330, Article No. 565. https://doi.org/10.1136/bmj.38380.674340.E0

[17] Mogren, I., Högberg, U., Winkvist, A. and Stenlund, H. (1999) Familial Occurrence of Preeclampsia. Epidemiology, 10, 518-522. https://doi.org/10.1111/j.1447-0756.2012.01990.x

[18] Shiozacy, A., Matsuda, Y., Satoh, S. and Saito, S. (2013) Comparison of Risk Factors for Gestational Hypertension and Preeclampsia in Japanese Singleton Pregnancies. Journal of Obstetrics and Gynaecology Research, 39, 492-499. https://doi.org/10.1111/j.1447-0756.2012.01990.x 